\title{
RESEARCH IN PARAMETERS OF ACCELERATION OF ELECTRIC VEHICLE DEPENDING ON TRANSMISSION GEAR RATIO
}

\author{
Dainis Berjoza, Inara Jurgena, Vilnis Pirs \\ Latvia University of Life Sciences and Technologies, Latvia \\ dainis.berjoza@1lu.lv, inara.jurgena@1lu.lv, vilnis.pirs@1lu.lv
}

\begin{abstract}
Electric vehicles become more widespread in European countries and in Latvia as well. One of the essential assemblies of an electric vehicle is its transmission. Electric vehicles are usually equipped with a transmission with a constant gear ratio. For this reason, it is important to choose a proper gear ratio. A gear ratio affects acceleration dynamics as well as the range per charge. The choice of an improper gear ratio can overload the motor, the controller or the batteries. The control unit of the experimental electric vehicle Renault Clio Electro was programmed for third gear of a standard gearbox. The paper analysed the acceleration dynamics of a converted electric vehicle by road testing the automobile. The electric vehicle was road tested in all five gears. Speed, acceleration distance and acceleration were measured by a scientific radar Stalker ATS. Besides acceleration characteristics, the research determined the electrical parameters of the electric vehicle, which allowed identifying the load of the batteries depending on the transmission gear ratio. After the data were processed, the research constructed the following curves: $v=f(t) ; s=f(t)$.
\end{abstract}

Key words: electric vehicle, gear ratio, acceleration.

\section{Introduction}

The dynamic parameters of automobiles are important not only as motor power characteristics, but also in relation to safety in critical situations. One of the dynamic characteristics is acceleration: maximum acceleration, average acceleration and the time of acceleration to $50 \mathrm{~km} \cdot \mathrm{h}^{-1}$ or $100 \mathrm{~km} \cdot \mathrm{h}^{-1}$. Technical characteristics of vehicles usually provide the average time of acceleration from 0 to $100 \mathrm{~km} \cdot \mathrm{h}^{-1}$. However, acceleration considerably changes depending on the speed reached and the gear engaged, and therefore it is usually not specified in technical data. The identification and recording of momentary acceleration values is usually a much more complicated process than the identification of the acceleration time, which could be approximately measured by means of a chronometer.

The research aim is to experimentally examine the acceleration parameters of a converted electric vehicle at various transmission gear ratios.

The researchers have designed a model for electric and hybrid vehicles. The model is based on a number of modules, for example, it considers the use of ultracapacitators. Some modules include factors affecting the characteristics of the motor, transmission, wheels, the vehicle as a whole and roads. FTP 75 and HWFET driving cycles were chosen for simulating a driving regime of the electric vehicle. The dynamic parameters chosen were as follows: the time of acceleration from 0 to various target speeds, for example, a speed of $100 \mathrm{~km} \cdot \mathrm{h}^{-1}$ had to be reached in $18.1 \mathrm{~s}$ and the maximum acceleration had to be $3.583 \mathrm{~m} \cdot \mathrm{s}^{-2}$. After optimisation, the maximum acceleration reached $4.07 \mathrm{~m} \cdot \mathrm{s}^{-2}$. Wheel slippage was also simulated at various coefficients of adherence in the range of 0.2-0.95. The research constructed graphs for motor power depending on time. The model was not compared with the experimental ones [1]. In a similar way, the model was employed to do research on optimising the torque of a hybrid automobile [2]. The research also simulated change in the angular speed of shafts depending on time.

A number of research investigations have been done on the use of ultracapacitators in electric automobiles. Ultracapacitators could be used as energy accumulators, for example, when doing regenerative braking. The research investigations have analysed a number of circuit schemes and regimes for ultracapacitators. The first acceleration regime employed two phases, without the ultracapacitator turned on, while afterwards it was turned on. The second regime represented regenerative braking that, at the beginning, charged the ultracapacitator and then the batteries [3].

The US researchers have done research on the impact of inertia of electric vehicles on energy consumption driving the automobiles according to various strategies [4]. They analysed all the driving regimes separately, for example, acceleration and deceleration. Their research mainly focused on saving fuel by choosing an optimum driving regime. The US researchers carried out an experiment on a roll test bench. Acceleration tests on the bench were mainly aimed at determining fuel consumption in various driving regimes. The experiment results were compared with the data acquired by a 
mathematical model [4]. The acceleration regime represented only a component of the whole research, and no acceleration tests were done separately.

Research investigations have been done into electric vehicle equipped with sodium-nickel chloride batteries, which are rarely used, in combination with ultracapacitators. The experiments were done in urban areas with intensive or quite intensive traffic. The experiments revealed that ultracapacitators decreased the time of acceleration from 0 to $80 \mathrm{~km} \cdot \mathrm{h}^{-1}$ by $38.5 \%$ and the power consumed from the batteries during acceleration by approximately $40 \%$ [5].

The scientists have developed an algorithm for the choice of parameters for electric automobiles to convert the vehicles from internal combustion to electric power [6]. The research gives a mathematical algorithm for calculation of a proper gear ratio, depending on the power and torque characteristics of the motor chosen. The research found a formula for calculation of the electrical current consumed, which took into account the instantaneous power of the motor and also the power consumed by the driving steering booster, the electric brake vacuum pump, the climate system and the lighting system. The research also found a formula for calculation of the theoretical capacity of batteries, depending on the distance to be driven. The algorithm was verified for the converted electric automobile Renault Clio equipped with an M2-AC25/4-A/L motor with a nominal power of $25 \mathrm{~kW}$ [6]. Based on the calculation results, the optimum gearbox ratio was chosen for the automobile, which was also used for programming the automobile for the conversion.

The theoretical continuous curves for the motor of the automobile are presented in technical parameter information [7]. The optimum range of motor speed to reach the maximum automobile speed was from 3500 to $4500 \mathrm{~min}^{-1}$. The electric automobile transmission has to ensure the motor operates within the mentioned range at the average operational speed of the automobile. The operational curves for a particular electric automobile could differ, depending on the controller used and the technical characteristics of the batteries.

The mentioned research investigations have not analysed in detail the acceleration characteristics of electric vehicles if changing the transmission gear ratio; accordingly, it is useful to do such research.

As the number of electric vehicles increases, the dynamic characteristics of electric automobiles, the ability to join the traffic flow as well as do various manoeuvres, for example, overtaking a vehicle accurately and dynamically, becomes important. An analysis of an acceleration-time curve allows identifying the average economical driving speed for an electric vehicle in non-urban driving, i.e. the maximum driving range at optimum fuel consumption. Converted electric vehicles are usually equipped with standard gearboxes, and the objective of engineers is to choose a proper transmission gear ratio for the gearbox, so that the best combination of dynamic and economic parameters is provided for the electric vehicle.

\section{Materials and methods}

The experiment employed a converted electric vehicle Renault Clio Electro. The key technical characteristics of the electric vehicle are presented in Table 1.

The experiment was carried out on a dry asphalt road with a rolling resistance coefficient of 0.015. During the experimental day, the speed of wind was less than $2 \mathrm{~m} \cdot \mathrm{s}^{-1}$, there was no precipitation. Before the experiment the batteries were warmed up by driving the automobile for 7-8 $\mathrm{km}$. The radar was placed 3-5 m away from the automobile. The acceleration experiment was done by at least two operators. One operator drove the vehicle, while the other one activated the radar. After the radar had been activated, a command was given to start driving.

The operator accelerated the electric vehicle as much as possible. The acceleration in first, second and fifth gears was done until the moment the speed did not increase for 2-3 $\mathrm{s}$. The acceleration in third and fourth gears was done up to a speed of $100 \mathrm{~km} \cdot \mathrm{h}^{-1}$. The experimental procedure was as follows: the vehicle was accelerated in the direction away from the radar, beginning with first, second, third, fourth and fifth gears. The experiment was replicated by repeating the same $1^{\text {st }}-5^{\text {th }}$ gear cycle. It was done purposefully, so that the degree of battery discharge could not affect the performance of the vehicle operated in various gears. 
Technical characteristics of the converted electric vehicle Renault Clio Electro

\begin{tabular}{|c|c|c|}
\hline No & Technical parameter & Value \\
\hline 1 & Electric motor type & HPEVS AC 51 \\
\hline 2 & Controller type & Sigma Drive PAC950TL02 \\
\hline 3 & Electric motor power & $30 \mathrm{~kW}$ \\
\hline 4 & Gearbox type & 5 -speed, manual \\
\hline 5 & Maximum speed & $110 \mathrm{kmh}^{-1}$ \\
\hline 6 & Total battery voltage & $102 \mathrm{~V}$ \\
\hline 7 & On-board power & $60 \mathrm{kWh}$ \\
\hline 8 & Range per charge & $4.0 \mathrm{~h}$ \\
\hline 9 & Battery charging time & \\
\hline
\end{tabular}

\section{Results and discussion}

After the experiment, the data recorded by the radar were processed. An average curve for change in acceleration for each gear, which was based on three experimental replications, was constructed. The curves for change in speed depending on time are shown in Figure 1.

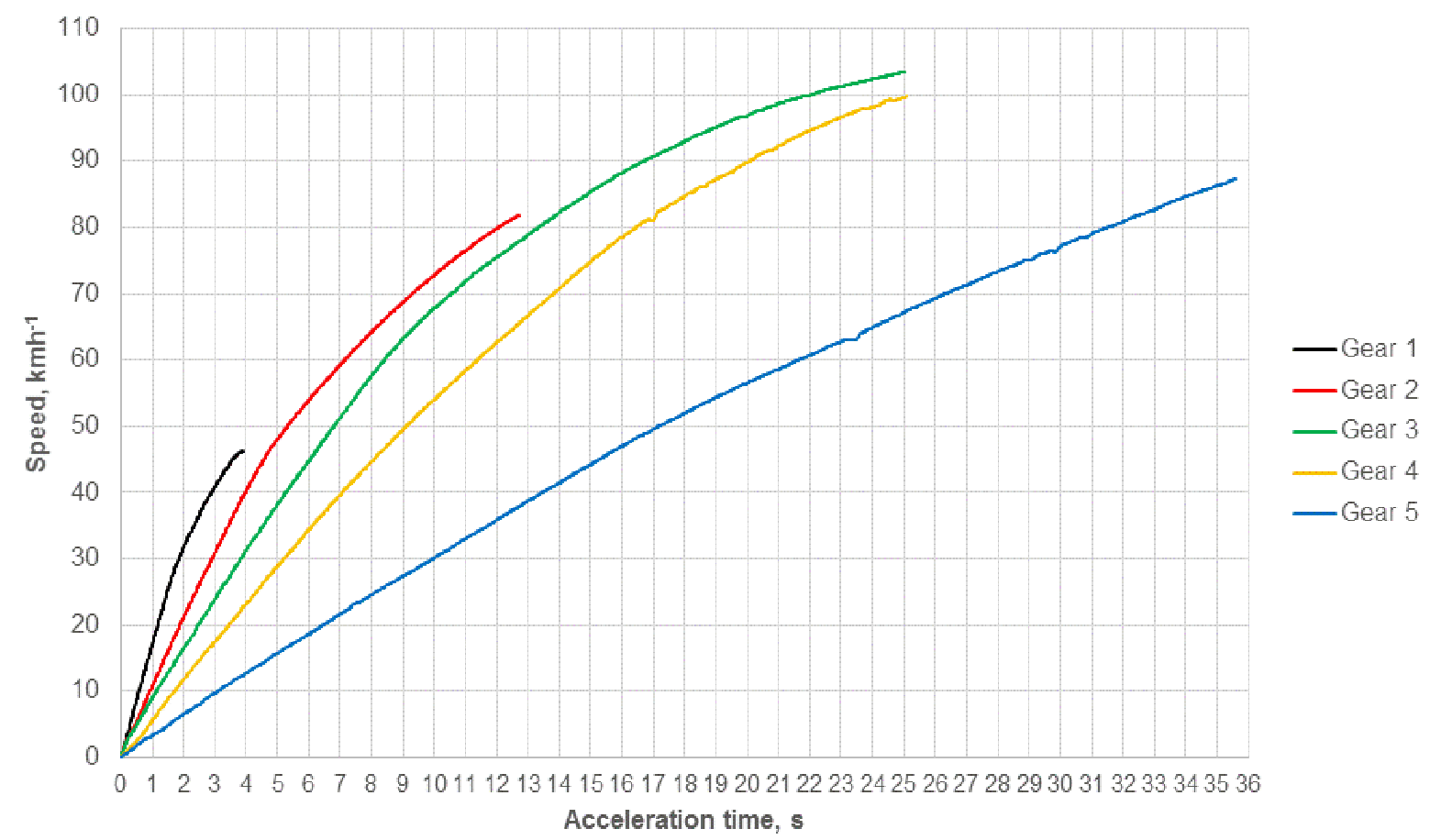

Fig. 1. Change in speed for electric vehicle Renault Clio Electro

The vehicle demonstrated the highest dynamism in first gear, reaching a speed of $46.3 \mathrm{~km} \cdot \mathrm{h}^{-1}$ in $3.91 \mathrm{~s}$. Since the vehicle was not equipped with a clutch, shifting gears was not advised. In view of the fact that the maximum speed allowed in urban areas could not be reached in first gear at the maximum motor speed, this gear should not be used in urban driving. In second gear, the maximum speed of $81.86 \mathrm{~km} \cdot \mathrm{h}^{-1}$ was reached in $12.73 \mathrm{~s}$. The dynamism of the vehicle in second gear, compared with that in first gear in the comparable speed range (up to $46 \mathrm{~km} \cdot \mathrm{h}^{-1}$ ), was on average $18-36 \%$ lower. In third gear, a speed of $100 \mathrm{~km} \cdot \mathrm{h}^{-1}$ was reached in $22.04 \mathrm{~s}$, while in fourth gear it took $25.10 \mathrm{~s}$. The highest speed was reached in third gear. The acceleration in fifth gear was very slow; therefore, this gear is not advised for driving. According to previous experimental data, fifth gear in non-urban driving does not allow achieving a longer driving range than third and fourth gears do.

Change in acceleration distance depending on time in all gears is shown in Figure 2.

In third gear, the experimental vehicle covered $400 \mathrm{~m}$ in $22.28 \mathrm{~s}$. In fourth gear, this distance was covered in $24.42 \mathrm{~s}$, while in fifth gear it took $32.18 \mathrm{~s}$. In fifth gear, it took $44.4 \%$ more time for the vehicle to cover $400 \mathrm{~m}$. An analysis of the acceleration of the vehicle up to the first $100 \mathrm{~m}$ revealed 
that in second gear it took $8.93 \mathrm{~s}$, reaching a speed of $68.36 \mathrm{~km} \cdot \mathrm{h}^{-1}$. In third gear, the vehicle covered this distance in $9.83 \mathrm{~s}$, reaching a speed of $67.11 \mathrm{~km} \cdot \mathrm{h}^{-1}$, while in fourth gear the vehicle covered $100 \mathrm{~m}$ in $11.35 \mathrm{~s}$, reaching a speed of $59.91 \mathrm{~km} \cdot \mathrm{h}^{-1}$. In fifth gear, the dynamism of the vehicle was considerably lower, and $100 \mathrm{~m}$ were covered in $15.33 \mathrm{~s}$, reaching a speed of $45.12 \mathrm{~km} \cdot \mathrm{h}^{-1}$.

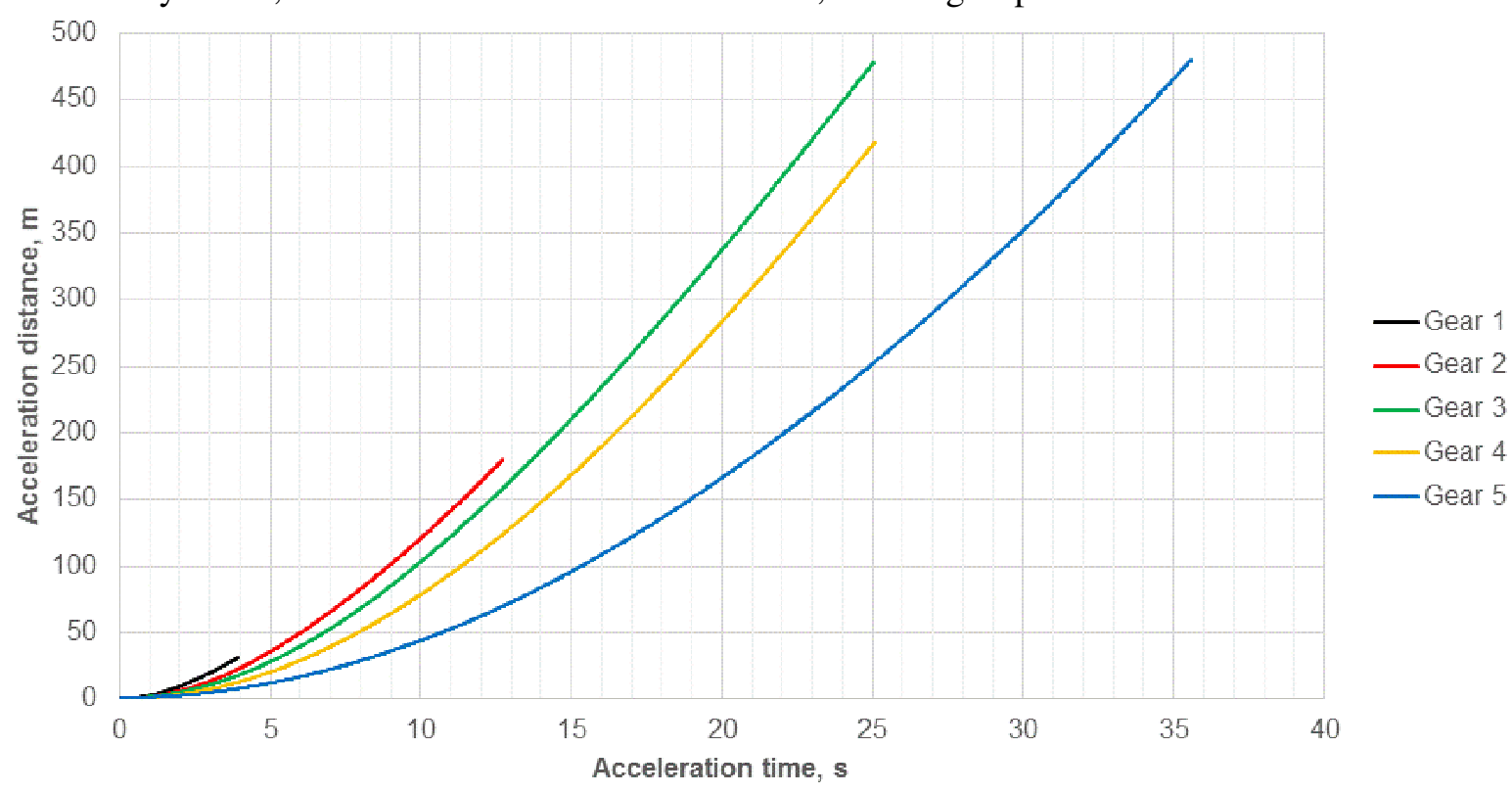

Fig. 2. Change in acceleration distance for electric vehicle Renault Clio Electro

For urban driving, it is important to analyse the performance of the vehicle within the maximum allowed speed, $50 \mathrm{~km} \cdot \mathrm{h}^{-1}$. In non-urban driving, it is important to reach a speed of $90 \mathrm{~km} \cdot \mathrm{h}^{-1}$. However, in view of the fact that the electric vehicle reached a speed of $90 \mathrm{~km} \cdot \mathrm{h}^{-1}$ only in third and fourth gears, the analysis was performed for a speed of $80 \mathrm{~km} \cdot \mathrm{h}^{-1}$. This speed could be reached in all gears, except the first one. The times needed to reach the speeds analysed are shown in Figure 3.

In first gear, the electric vehicle reached a speed of $46.30 \mathrm{~km} \cdot \mathrm{h}^{-1}$ in $3.91 \mathrm{~s}$, not exceeding the speed threshold of $50 \mathrm{~km} \cdot \mathrm{h}^{-1}$. In second gear, it reached a speed of $50 \mathrm{~km} \cdot \mathrm{h}^{-1}$ in $5.32 \mathrm{~s}$, which was the best performance in terms of dynamism. In third gear, the time of acceleration up to $50 \mathrm{~km} \cdot \mathrm{h}^{-1}$ was $28 \%$ longer, while in fourth gear it was $71.4 \%$ longer. In fifth gear, a speed of $50 \mathrm{~km} \cdot \mathrm{h}^{-1}$ was reached in a 3.2-fold longer time. A similar trend was observed for reaching a speed of $80 \mathrm{~km} \cdot \mathrm{h}^{-1}$, which, in second gear, took $12.06 \mathrm{~s}$. In second gear, this speed was reached in $10.5 \%$ longer time, while in third gear in $36.3 \%$ longer time. A speed of $80 \mathrm{~km} \cdot \mathrm{h}^{-1}$ was reached in fifth gear in 1.91-fold longer time than that in fourth gear and in 2.36-fold longer time than that in third gear.

The acceleration distances needed to reach the speeds of 50,80 and $90 \mathrm{~km} \cdot \mathrm{h}^{-1}$ for the electric automobile Renault Clio Electro are presented in Figure 4.

The shortest acceleration distance, $40.12 \mathrm{~m}$, to reach a speed of $50 \mathrm{~km} \cdot \mathrm{h}^{-1}$ was achieved in second gear, while in third gear it was $50.25 \mathrm{~m}$, which was $25.2 \%$ more. Reaching a speed of $50 \mathrm{~km} \cdot \mathrm{h}^{-1}$ in fourth gear required $65.94 \mathrm{~m}$, or a $31.3 \%$ longer distance. Reaching this speed in fifth gear required a 2.5-fold longer distance than that in third gear. According to the experimental data, reaching a speed of $80 \mathrm{~km} \cdot \mathrm{h}^{-1}$ in second and third gears was almost the same, and the performance differed only by $4.1 \%$. The distances covered to reach a speed of $80 \mathrm{~km} \cdot \mathrm{h}^{-1}$ in third and fourth gears increased by $16.4 \%$. Just like for the other parameters, the acceleration distance in fifth gear considerably (2.2fold) exceeded that in third gear.

From the perspective of vehicle dynamism, it is advised to drive a converted electric vehicle in second gear in urban traffic. In non-urban traffic, it is advised to use third gear, as the dynamism of the vehicle does not decrease considerably and it is a relatively short time to reach the speed allowed in non-urban traffic, $90 \mathrm{~km} \cdot \mathrm{h}^{-1}$. 


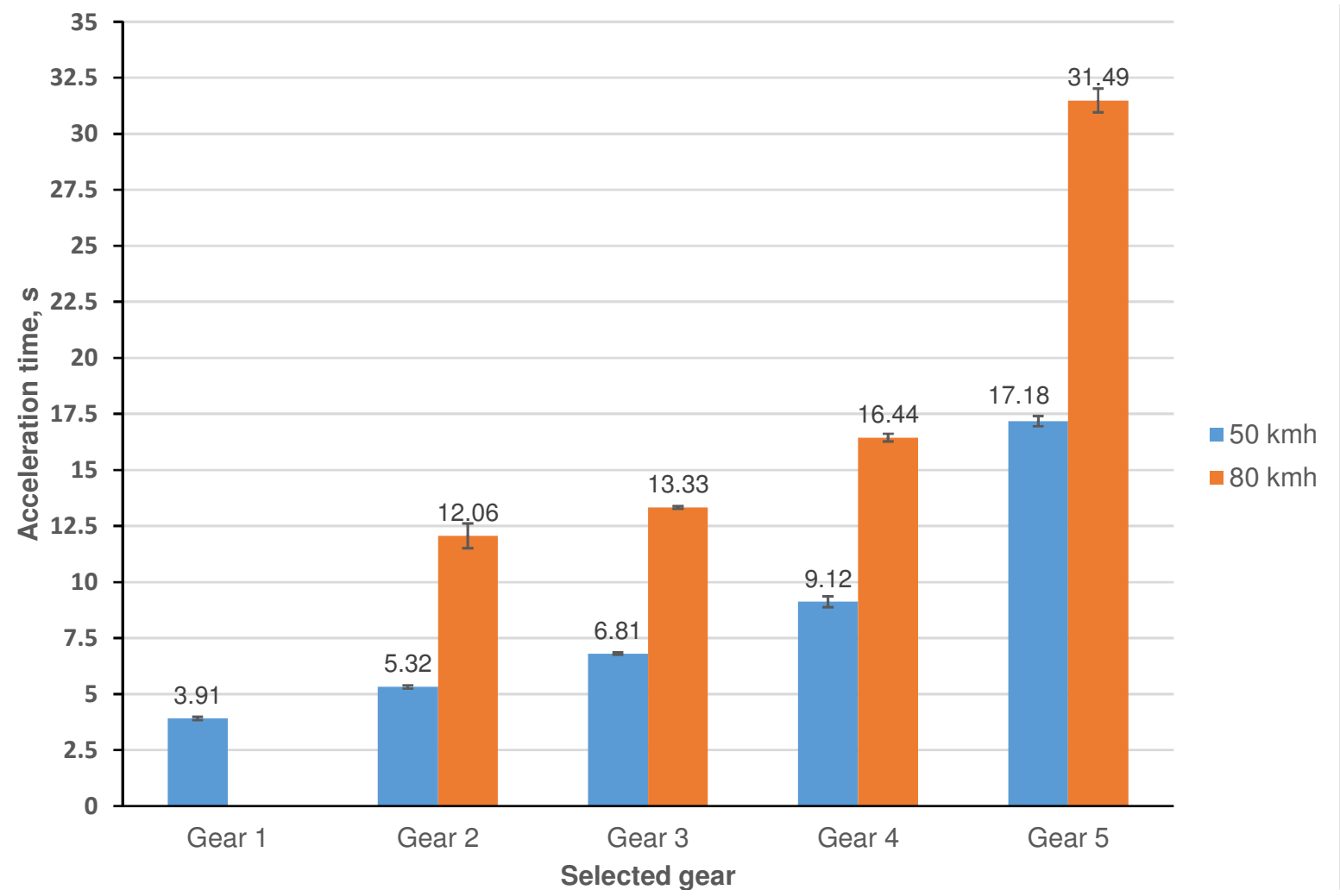

Fig. 3. Acceleration times needed to reach speeds of 50,80 and $90 \mathrm{~km} \cdot \mathbf{h}^{-1}$ for electric vehicle Renault Clio Electro

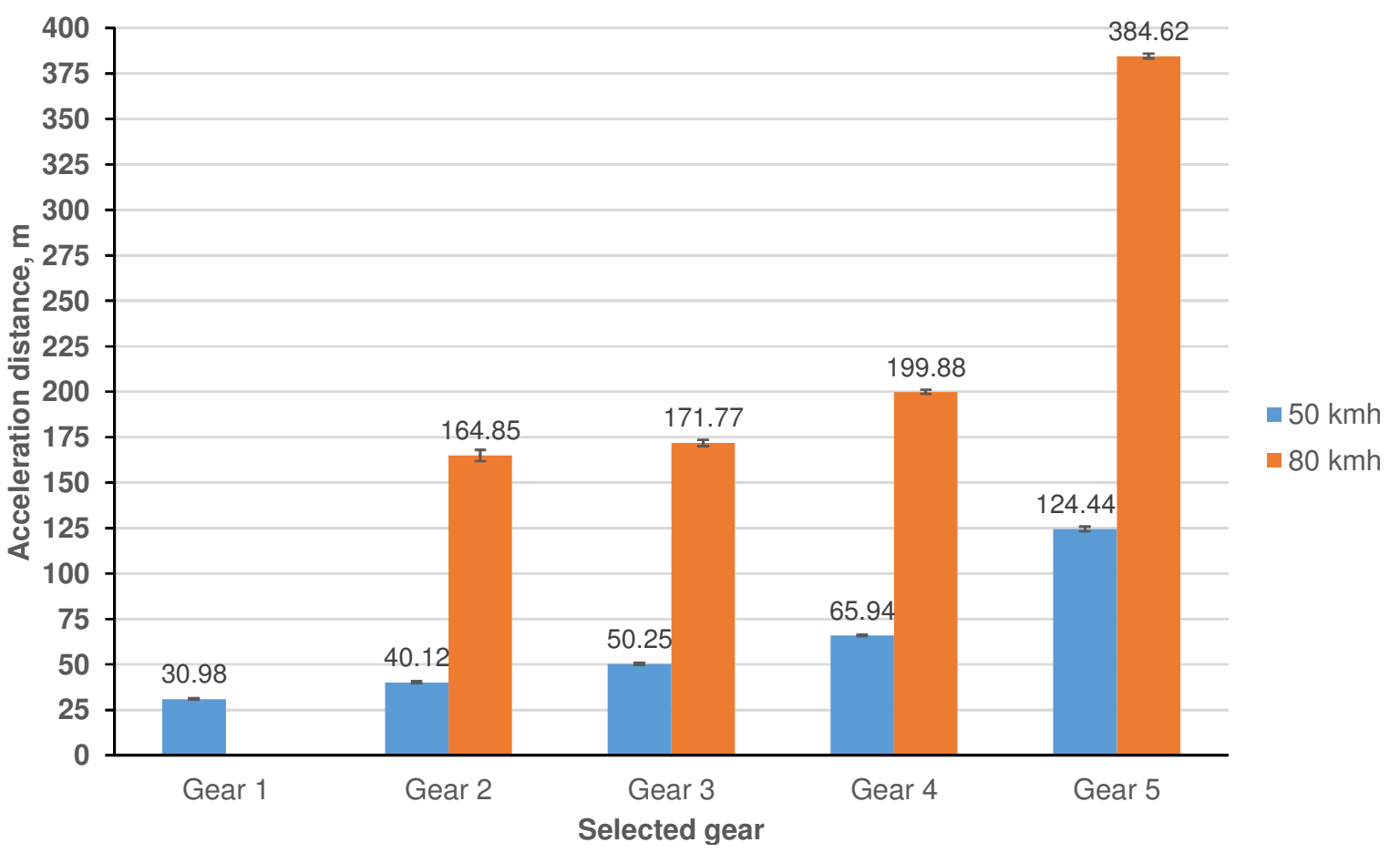

Fig. 4. Acceleration distances needed to reach speeds of 50,80 and $90 \mathbf{~ k m} \cdot \mathbf{h}^{-1}$ for electric automobile Renault Clio Electro

\section{Conclusions}

1. Other researchers have insufficiently focused on experimental analyses of the dynamism of electric vehicles depending on the transmission gear ratio. 
2. Most of the researchers have performed relevant simulations by employing various mathematical models and tools. There are available some in-depth research investigations into the use of ultracapacitators to relieve the batteries during acceleration and to achieve higher dynamic parameters.

3. The shortest time of acceleration from 0 to $46.3 \mathrm{~km} \cdot \mathrm{h}^{-1}$ was achieved in first gear, $3.9 \mathrm{~s}$, yet this gear cannot be used even in urban driving, as it does not allow reaching a speed of $50 \mathrm{~km} \cdot \mathrm{h}^{-1}$.

4. High dynamism was demonstrated by the electric vehicle in second gear, reaching a speed of $81.86 \mathrm{~km} \cdot \mathrm{h}^{-1}$ in $12.73 \mathrm{~s}$. In second gear, the vehicle covered the first 100 meters in $8.93 \mathrm{~s}$ and reached a speed of $68.36 \mathrm{~km} \cdot \mathrm{h}^{-1}$; the vehicle accelerated to a speed of $50 \mathrm{~km} \cdot \mathrm{h}^{-1}$ over a distance of $40.12 \mathrm{~m}$ in $5.32 \mathrm{~s}$. It is advised to use second gear in urban driving, not exceeding a speed of $70 \mathrm{~km} \cdot \mathrm{h}^{-1}$.

5. The maximum speed was reached in third gear. The vehicle accelerated to a speed of $100 \mathrm{~km} \cdot \mathrm{h}^{-1}$ in $22.04 \mathrm{~s}$. The dynamism of the vehicle in third gear was lower than that in second gear, yet it is advised to use this gear in non-urban driving. The vehicle could cover a 100-meter acceleration distance in $9.83 \mathrm{~s}$ and reach a speed of $90 \mathrm{~km} \cdot \mathrm{h}^{-1}$ in $16.68 \mathrm{~s}$, covering a distance of $251.4 \mathrm{~m}$.

6. In fourth gear, the vehicle reached a speed of $50 \mathrm{~km} \cdot \mathrm{h}^{-1}$ in $9.12 \mathrm{~s}$ and a speed of $90 \mathrm{~km} \cdot \mathrm{h}^{-1}$ in $20.06 \mathrm{~s}$. It is not advised to use this gear for acceleration, as the distance covered to reach a speed of $90 \mathrm{~km} \cdot \mathrm{h}^{-1}$ was $13 \%$ longer than that in third gear.

7. In fifth gear, the dynamic parameters of the electric vehicle were two or even more times lower than those in third gear; therefore, it is not advised to use this gear either in urban or non-urban driving.

8. To determine acceleration parameters for electric vehicles in a convenient and easy-to-use way, it is necessary to develop a data processing methodology based on the parameters saved in a data logger. In this way, it would be possible to carry out experiments on road sections having higher traffic intensity that those used by the experiment with a scientific radar.

\section{References}

[1] Wenzhong Gao D., Mi C., Emadi A. Modeling and simulation of electric and hybrid vehicles. Tools that can model embedded software as well as components, and can automate the details of electric and hybrid vehicle design, need to be developed. Proceedings of the IEEE, vol. 95, Nr.4, April 2007, pp. 729-745.

[2] Chen L., Xi G., Sun J. Torque coordination control during mode transition for a series-parallel hybrid electric vehicle. IEEE Transactions of vehicular technology, vol. 61, Nr.7, September 2012, pp. 2936-2949.

[3] Cao J., Emadi A. A new battery/ultracapacitor hybrid energy storage system for electric, hybrid, and plug-in hybrid electric vehicles. IEEE Transactions on power electronics, vol. 27, Nr.1, January 2012, pp. 122- 132 .

[4] Lee J. Vehicle inertia impact on fuel consumption of conventional and hybrid electric vehicles using acceleration and coast driving strategy. Dissertation. Virginia, 2009, $136 \mathrm{p}$.

[5] Dixon J., Nakashima I., Arcos E. F. etc. Electric vehicle using a combination of ultracapacitors and zebra battery. IEEE Transactions on industrial electronics, vol. 57, Nr.3, March 2010, pp.943949.

[6] Berjoza D., Pirs V. Automobile technical solutions and selection of parameters for rebuilding into electormobile. Proceedings of International conference "Engineering for rural development", May 24-25, 2012, Jelgava, Latvia, pp. 324-330.

[7] HPEVS AC-51 Imperial continuous graph 96 Volt Vented fan cooled. Peak and continuous power graphs for HPEVS AC-51 motor. [online] [20.02.2019.] Available at: http://www.hpevs.com/Site/images/torque-curves/ac-

51/96\%20volt/Imperial\%20pdf\%20graphs/AC51\%2096\%20volt\%20650\%20amp/Continuous\%2 0graphs/ac51\%2096\%20volt\%20650\%20amp\%20imperial\%20continuous\%20graph\%20FC.pdf 